University of South Florida

DIGITAL COMMONS

@ UNIVERSITY OF SOUTH FLORIDA
Digital Commons @ University of

South Florida

8-1-2006

\title{
Bus Accident Reporting, Tracking and Analysis System
}

CUTR

Follow this and additional works at: https://digitalcommons.usf.edu/cutr_nctr

\section{Recommended Citation}

"Bus Accident Reporting, Tracking and Analysis System," National Center for Transit Research (NCTR) Report No. CUTR-NCTR-RR-2004-07, Center for Urban Transportation Research, University of South Florida, 2006.

DOI: https://doi.org/10.5038/CUTR-NCTR-RR-2004-07

Available at: https://scholarcommons.usf.edu/cutr_nctr/176

This Technical Report is brought to you for free and open access by the National Center for Transit Research (NCTR) Archive (2000-2020) at Digital Commons @ University of South Florida. It has been accepted for inclusion in Research Reports by an authorized administrator of Digital Commons @ University of South Florida. For more information, please contact digitalcommons@usf.edu. 


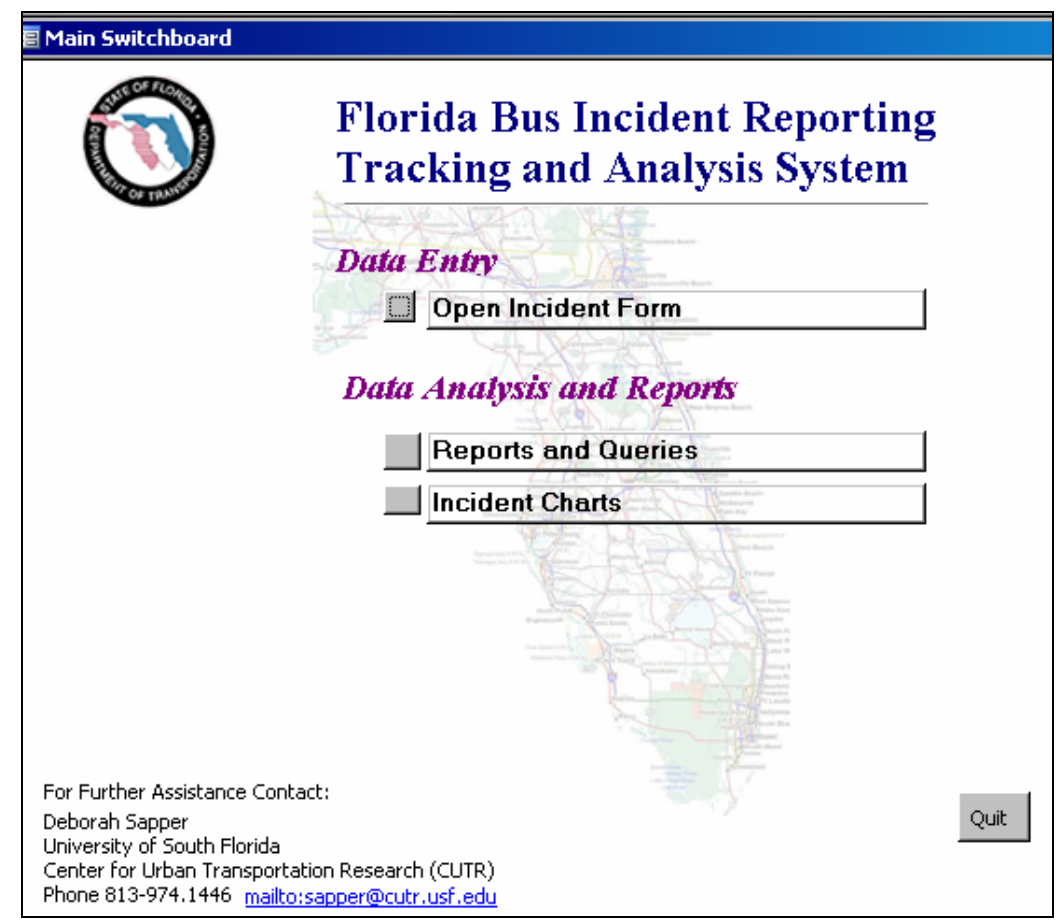

Bus Incident Reporting, Tracking and Analysis System 


\section{Disclaimer}

The opinions, findings, and conclusions expressed in this publication are those of the authors and not necessarily those of the State of Florida Department of Transportation. 


\begin{tabular}{|c|c|c|c|c|}
\hline & \multicolumn{2}{|c|}{ 2. Government Accession No. } & \multicolumn{2}{|c|}{ 3.Recipient's Catalog No. } \\
\hline \multirow{3}{*}{\multicolumn{3}{|c|}{$\begin{array}{l}\text { 4.Title and Subtitle } \\
\text { Bus Incident Reporting, Tracking and Analysis System }\end{array}$}} & \multirow{2}{*}{\multicolumn{2}{|c|}{$\begin{array}{l}\text { 5.Report Date } \\
\text { August } 2006\end{array}$}} \\
\hline & & & & \\
\hline & & & \multicolumn{2}{|c|}{ 6.Performing Organization Code } \\
\hline \multicolumn{3}{|c|}{$\begin{array}{l}\text { 7.Author(s) } \\
\text { Deborah Buchacz Sapper \& Amber Reep }\end{array}$} & \multicolumn{2}{|c|}{ 8.Performing Organization Report } \\
\hline \multirow{2}{*}{\multicolumn{3}{|c|}{$\begin{array}{l}\text { 9.Performing Organization Name and Address } \\
\text { National Center for Transit Research } \\
\text { Center for Urban Transportation Research } \\
\text { University of South Florida } \\
4202 \text { E. Fowler Avenue, CUT100 } \\
\text { Tampa, FL 33620-5375 }\end{array}$}} & \multicolumn{2}{|c|}{ 10. Work Unit No. } \\
\hline & & & \multicolumn{2}{|c|}{$\begin{array}{l}\text { 11.Contract or Grant No. } \\
\text { DTRS98-G-0032 }\end{array}$} \\
\hline \multicolumn{3}{|c|}{$\begin{array}{l}\text { 12.Sponsoring Agency Name and Address } \\
\text { Office of Research and Special Programs } \\
\text { U.S. Department of Transportation, Washington, D.C. } 20690\end{array}$} & \multicolumn{2}{|c|}{$\begin{array}{l}\text { 13. Type of Report and Period } \\
\text { Covered }\end{array}$} \\
\hline \multicolumn{3}{|c|}{$\begin{array}{l}\text { Florida Department of Transportation } \\
605 \text { Suwannee Street, MS 26, Tallahassee, FL } 32399\end{array}$} & \multicolumn{2}{|c|}{ 14.Sponsoring Agency Code } \\
\hline \multicolumn{5}{|l|}{ 15.Supplementary Notes } \\
\hline \multicolumn{5}{|c|}{$\begin{array}{l}\text { Supported by a grant from the Florida Department of Transportation and the U.S. Department of } \\
\text { Transportation }\end{array}$} \\
\hline \multicolumn{5}{|c|}{$\begin{array}{l}\text { Many Florida transit systems do little formal analysis of all accidents on an aggregate basis. } \\
\text { In many transit system accidents and incidents are not being tracked or analyzed to identify } \\
\text { common trends from types of incidents, location, driver, bus route, roadway characteristics and } \\
\text { other variables that may reduce transit incidents in the future. }\end{array}$} \\
\hline \multicolumn{5}{|c|}{$\begin{array}{l}\text { The goal of the project was to develop a basic bus incident reporting system for bus transit } \\
\text { accidents and security incidents for Florida's public transit agency. This project will allow } \\
\text { transit systems to easily enter and track types of accident and incidents by developing incident } \\
\text { forms, along with the ability to analyze and report common trends in accident data over time. } \\
\text { Another goal of the project was to develop a system that in the future could easily transfer the } \\
\text { database and data to a statewide web-based incident tracking system. }\end{array}$} \\
\hline $\begin{array}{l}\text { 17.Key Words } \\
\text { Public Transit, Safety, } \\
\text { Accidents }\end{array}$ & \multicolumn{4}{|c|}{$\begin{array}{l}\text { 18.Distribution Statement } \\
\text { Available to the public through the National Technical Information } \\
\text { Service (NTIS),5285 Port Royal Road, Springfield, VA } 22181 \text { ph (703) } \\
487-4650 \text { http://www.ntis.gov , and through the NCTR web sit at } \\
\text { http://www.nctr.usf.edu/. }\end{array}$} \\
\hline $\begin{array}{l}\text { 19.Security Classif. (of this } \\
\text { report) }\end{array}$ & $\begin{array}{l}\text { 20.Security Classif. } \\
\text { (of this page) } \\
\text { Unclassified }\end{array}$ & 21.No. of pc & & 22. Price \\
\hline
\end{tabular}

Form DOT F 1700.7 (8-69) 


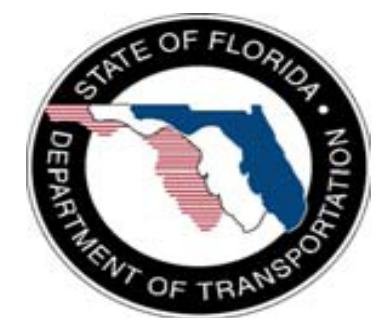

\section{Florida Department of Transportation}

Public Transit Office 605 Suwannee Street

Tallahassee, FL 32399-0450

(850) 414-4500

Project Manager:

Mike Johnson

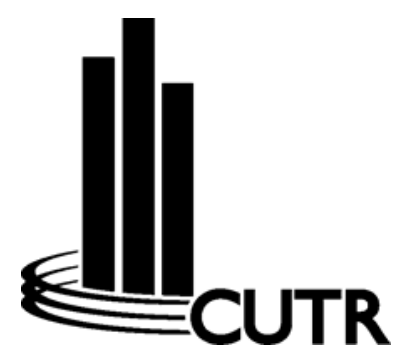

\footnotetext{
National Center for Transit Research Center for Urban Transportation Research

University of South Florida

4202 E. Fowler Avenue, CUT 100

Tampa, FL 33620-5375

(813) 974-3120
}

Project Staff: Deborah Buchacz Sapper, Senior Research Associate Amber Reep, Senior Research Associate 


\section{Table of Contents}

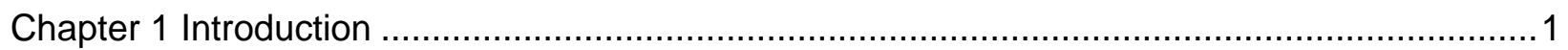

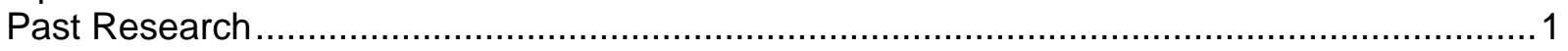

Chapter 2 State and Nationwide Implications …….......................................................

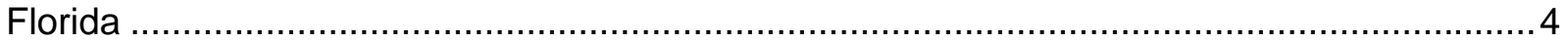

Chapter 14-90.004 FAC, Bus Transit System Operational Standards............................. 4

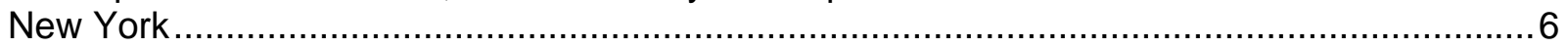

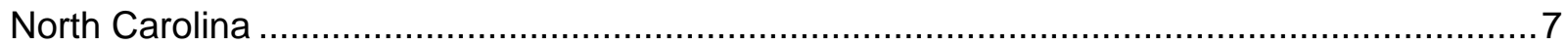

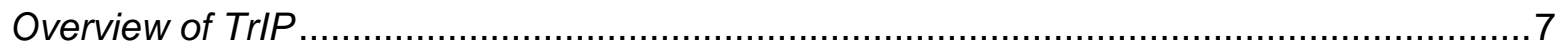

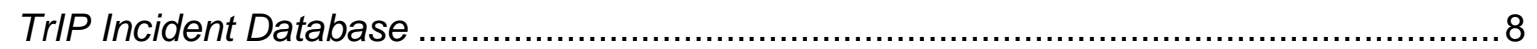

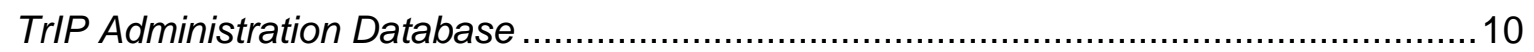

Analysis of North Carolina TrIP Database ...............................................................11

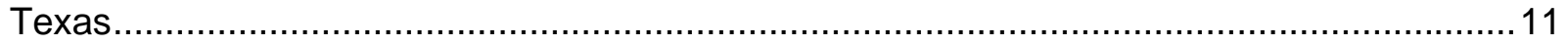

Chapter 3 Florida Bus Incident Reporting Tracking and Analysis System .............................13

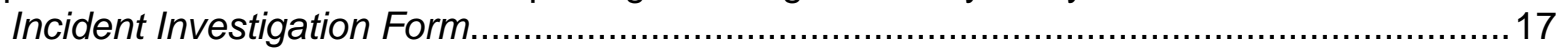

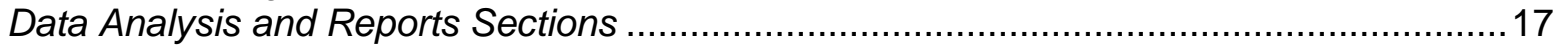

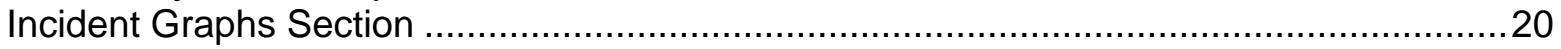

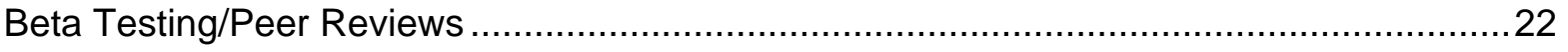

Chapter 4 Future Web Based Incident Tracking Database …….........................................24

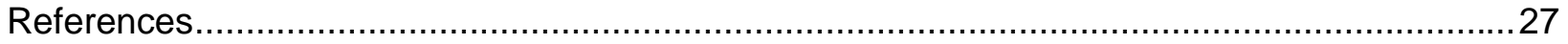

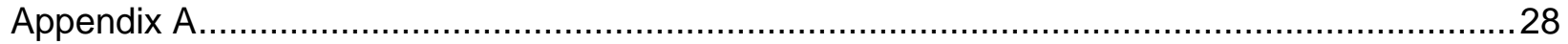

Florida Department of Transportation, Fixed Guideway Transportation System Online Safety

and Security Oversight Document Management

\section{List of Tables}

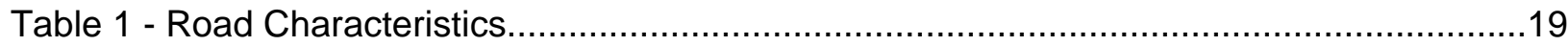

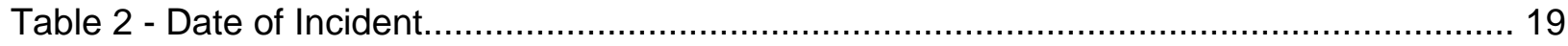

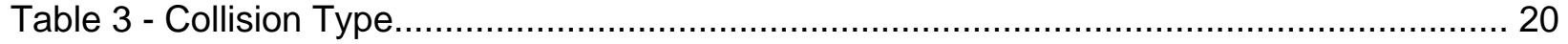

\section{LIST OF FIGURES}

Figure 1 -TrIP Incident Information Entry Form …........................................................ 9

Figure 2 - TxDOT Transit Vehicle Incident Reporting Form (Form PTN-101) ......................... 12

Figure 3 - Incident Reporting, Tracking and Analysis System ....................................... 13

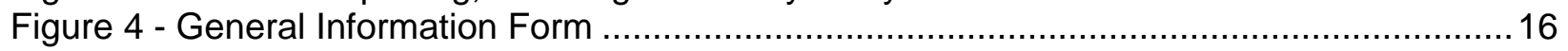

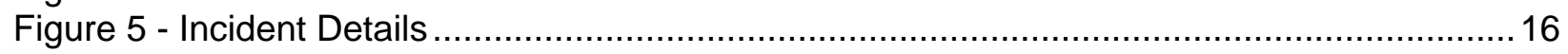

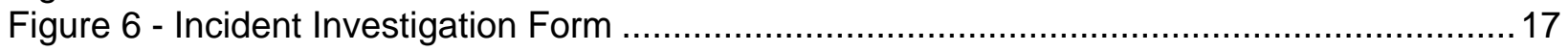

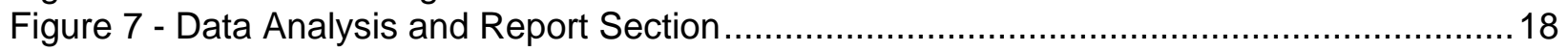

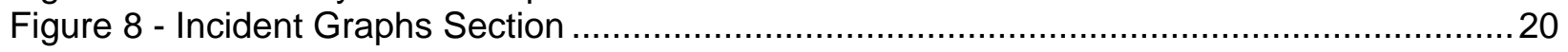

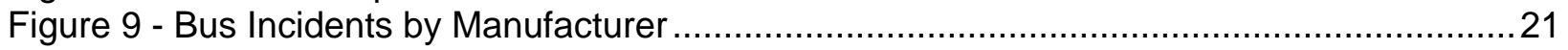

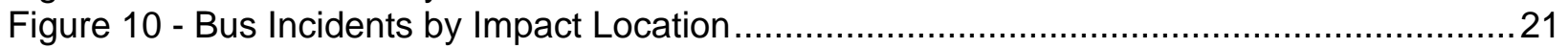

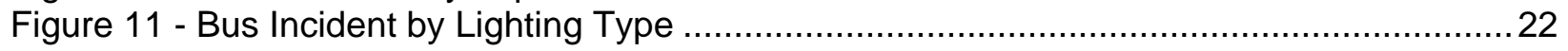




\section{Chapter 1 Introduction}

Through its National Center for Transit Research (NCTR), and under contract with the Florida Department of Transportation (FDOT), the Center for Urban Transportation Research (CUTR) at the University of South Florida was tasked with developing a bus accident and security incident reporting system for Florida's public transit systems. The bus incident and reporting system will enable transit systems to easily track, analyze, and report accidents, security incidents and other minor incidents such as slips and falls, as well as wheelchair incidents. This project, using Microsoft Office Access, will enable transit systems to enter accident and security incident information into a form, run queries and view reports. The Florida Bus Incident Reporting, Tracking and Analysis System will provide transit systems with a standardized tracking and reporting system that will enable electronic tracking and analysis of incident data at each agency and in the future at the statewide level.

\section{Past Research}

Under the National Center for Transit Research (NCTR), CUTR has produced a series of research reports on the topic of bus accident data and tracking.

In 1998, a report entitled "Enhancing Safety in Florida Transit Systems" was produced. One of the objectives of the study was to evaluate and document the current state and Federal regulations regarding safety in the public transit industry. This research also looked at how Florida's transit systems track and analyze bus accidents. From the information gathered in this report, it appeared that Florida was ahead of many other states due to the fact that Florida's transit systems were already required by State law to produce System Safety Program Plans and were already reporting and tracking accidents. However, it was noted that a standardized data collection process was missing.

In 2001, an NCTR study entitled "Analysis of Florida Transit Bus Crashes" was conducted. This project was to increase agency capabilities in tracking, analyzing and preventing transit bus crashes with the hope that systems could help reduce their related accident costs, while also making transit a safer and more attractive transportation alternative. The Hillsborough Area Regional Transit (HART) and the Central Florida Transit Authority (LYNX), two of the larger transit systems in Florida were selected, and their accident data were reviewed and analyzed. Following the review of the agencies' data, the report developed a five-step process that could be followed by transit systems when analyzing crash occurrence data and developing 
corrective action plans. The report also provided a useful list of crash occurrence characteristics (core and supplemental), which are needed to provide a thorough analysis and basis for safety campaigns designed to address the reasons for the accidents in the first place.

The five steps identified to analyze crash data and develop corrective action plans include:

- Collection of the data

- Preparation of the data for analysis

- Analysis of the data

- Interpretation of the results

- Action plan to deal with identified problems/issues

A core set of incident occurrence data was also developed in "Analysis of Florida Transit Bus Crashes" that include following data fields:

- Date, day of week, time of day

- Specific location of occurrence

- Roadway geometry (lanes, speed limits, traffic control and configuration)

- Roadway conditions

- Light conditions

- Route number, bus number

- Vehicle type, manufacture and year

- Operator hire, longevity, termination date (if actual)

- Date of operator's last training (refresher) course

- Occurrence dynamic (head on, sideswipe, angle, rear end, backing, front)

- Type of involvement (fixed object, moving object, parked vehicle, pedestrian, other bus, bike)

- Identified preventability status of occurrence

Supplemental data points to enhance incident analysis were recommended and included the following characteristics:

- Location of stop

- Roadway surface type

- Weather conditions

- Traffic conditions

- Observed vehicle defects at time of occurrence and date of last preventive maintenance

- Operator status (regular operator, mini-run, extra board, supervisor, etc.)

- Transit vehicle movement prior to/at time of occurrence 
- Movements of other vehicles involved prior to/at time of occurrence

- Pedestrian/cyclist movement prior to/at time of occurrence

- Passenger movement prior to/at time of occurrence

- Observed condition of other driver/pedestrian/cyclist/passenger

- Contributory factors

- Evasive action taken by driver

In 2004, CUTR undertook a similar study again entitled "Analysis of Florida Transit Bus Accidents"; however, this report focused on accident analysis at four of the mid-sized bus agencies in Florida: Gainesville Regional Transit System (RTS), Sarasota County Transportation Authority (SCAT), Volusia County Public Transit System (VOTRAN) and Lee County Regional Transit System (LeeTran). The report collected and analyzed accident data based on the "core" and "supplemental" data identified in the 2001 report. Also, in this project, a Microsoft Office Access accident database form was developed for accident tracking and analysis for small rural agencies in order for them to move from manual reporting (accident data in file cabinet) to an accident database. 


\section{Chapter 2 State and Nationwide Implications}

When reviewing accident reporting standards among the various state Departments of Transportation, one commonality was found. A few states have developed standards for System Safety Program Plans (SSPP), which include accident reporting and investigation procedures. However, most states have not adopted legislative mandates for the bus transit accident reporting and few states have developed standardized accident reporting systems either CD-based and/or web-based. However, some states have gone beyond the requirements of their SSPP plans outlining the accident reporting and investigation procedures. CUTR has identified some of these programs and states in the following pages.

\section{Florida}

Under the Florida Administrative Code (FAC), public transit operators in Florida must adhere to operational standards and practices. As part of Chapter 14-90, FAC bus transit systems must develop and adopt System Safety Program Plans (SSPP) and Security Program Plans (SPP) on an annual basis. As part of the SSPP, transit systems must follow the required operational standards for the reporting, tracking, reviewing and follow-up activities of accidents/incidents involving public transit vehicles. The actual standard cites the following:

\section{Chapter 14-90.004, FAC, Bus Transit System Operational Standards}

(5) Each bus transit system shall investigate, or cause to be investigated, any event involving a bus or taking place on bus transit system controlled property resulting in a fatality, injury, or property damage as follows:

(a) A fatality, where an individual is confirmed dead within 30 days of a bus transit system related event, excluding suicides and deaths from illnesses.

(b) Injuries requiring immediate medical attention away from the scene for two or more individuals.

(c) Property damage to bus transit system bus(es), non-bus transit system vehicles, other bus system property or facilities, or any other property, except the bus transit system shall have the discretion to investigate events resulting in property damage less than $\$ 1,000$. 
(d) Evacuation of a bus due to a life safety event where there is imminent danger to passengers on the bus, excluding evacuations due to operational issues.

(6) Each investigation shall be documented in a final report that includes a description of investigation activities, identified causal factors, and any identified corrective action plan.

(a) Each corrective action plan shall identify the action to be taken by the bus transit system and the schedule for its implementation.

(b) The bus transit system must monitor and track the implementation of each corrective action plan.

(7) Investigation reports, corrective action plans, and related supporting documentation shall be maintained by the bus transit system a minimum of four years from the date of completion of the investigation.

(8) On or before July 1, 2006, every bus transit system shall comply with the 2005 amendments to this rule.

Over the past five years, the Florida Department of Transportation's Public Transit Office has supported a variety of research projects regarding accident/incident investigation and reporting. As noted previously, in the NCTR Report entitled "Analysis of Florida Transit Bus Accidents" (December 2004), a very basic Microsoft Access database program was developed for small and medium sized transit systems to use for accident/incident data collection and reporting. The parameters included for collection were based upon the core set of incident occurrence data identified at the outset of this chapter. The 2004 NCTR report utilized this database program to analyze the accident data from four of the state's small and medium sized transit systems. The database has been made available for all transit system within the state and nationally on the Transit Bus Safety Resource web site under the Core Elements - Safety Data Acquisition and Analysis http://www.cutr.usf.edu/bussafety/core/data.htm.

Under the current research being conducted, a Microsoft Access tracking, analysis and reporting system is being developed and would complement the CDbased accident reporting system developed in the previous study. 


\section{New York}

In New York, the Public Transportation Safety Board (PTSB) is a state created board responsible for investigating and analyzing serious transit accidents and recommending actions that reduce the occurrence of such future incidents. The PTSB has broad, legislatively mandated powers to enable it to fulfill its mission, including:

- establishing accident reporting, investigation and analysis procedures

- conducting comprehensive accident investigations

- taking a proactive role in public safety by reviewing, approving and monitoring system safety program plans submitted by each public transportation system

- conducting system safety program field audits

- analyzing critical safety issues and concerns

- recommending the establishment of new safety legislation, rules and regulations, and transportation system procedures based on accident investigations, special studies and audits

In addition to meeting on a regular basis to review accident reports, investigation procedures and recommending new rules and regulations regarding such incidents. The Board's Safety Oversight Program makes on-site visits to the various statewide transit systems to ensure adherence to System Safety Program Plans and conducts safety audits. In addition, transit systems' security plans and programs are also reviewed as part of the oversight process.

In addition to on-site visits to the transit systems, the PTSB also spends a significant amount of time on training for the transit properties. Several classes conducted in the past few years have focused on transit accident management and investigation, as well as determining accident preventability and training needed to avoid reoccurrence of such events. Under current state law, each transit agency that falls under the jurisdiction of the PTSB must be trained and certified in the courses offered to ensure each transit property adheres to the latest safety and security requirements.

Under state law, each transit agency that falls under the jurisdiction of the PTSB must notify the PTSB of any of the following incidents:

- all accidents that result in a fatality

- all accidents which result in five or more injuries that require medical attention

- all accidents caused by mechanical failure including; but not limited to, all fires that occur in revenue service that require passenger evacuation and/or response by the police or fire departments 
Currently, 68 small bus systems (1-24 buses), 23 medium-sized bus systems (25-199 buses) and 16 large bus systems (over 200 buses) fall under the jurisdiction of the PTSB. While each transit agency must report incidents based on the above mentioned criteria, the PTSB reviews significant transit accidents and produces an annual summary outlining identified types and causes of such accidents. The PTSB also identifies probable causes of the accidents and produces summary analysis of all accidents on an annual basis. From these analyses, the PTSB is able to make recommendations for bus driver training, bus vehicle designs, maintenance procedures to ensure supervisory and mechanic accountability, commitment of capital resources to improve safety deficiencies, emergency communications, preventive maintenance procedures, emergency plans and procedures, and hours of service and fatigue.

\section{North Carolina}

North Carolina stands out among the states when it comes to public transit accident tracking and reporting. North Carolina Department of Transportation (NCDOT) has developed a comprehensive web-based database program to help transit systems track and monitor employee information, training, vehicles, customer comments, incidents, scheduling, dispatch, and billing. The software program is called TrIP, which stands for Transportation Information Programs.

\section{Overview of TrIP}

TrIP serves as a useful tool for handling information collected by transit systems. TrIP contains user-friendly menus, entry forms, and reports to create a package that is convenient and easy for database managers and employees that may be less familiar with database software. The software was designed to be easy to navigate through and the user modules provide concise instruction and guidance to provide quick data entry and analysis of incidents, customer feedback, and driver schedules. The modules help eliminate the duplication of data and allow for cross-tabulation for better analysis. These databases were created in Microsoft Access. Because of this, it is very useful for each user to understand database concepts and MS Access.

The templates were originally setup for the Winston-Salem Transit Authority as part of the Urban Transit Assistance Program. (This program was created by the Institute for Transportation Research and Education (ITRE) at North Carolina State University for the NCDOT Public Transportation Division (PTD) to offer technology assistance to transit providers across the state to improve operations and customer service.) 
All TrIP products are available free of charge to North Carolina transportation providers. Providers outside of North Carolina should contact the NCDOT regarding use of the software.

There are five distinct databases developed under TrIP: TrlP Administration, TrIP Incident, TrIP Notes, TrIP Maker and TrIP Export. For the purpose of this analysis only the TrIP Incident and Administration Databases will be reviewed.

\section{TrIP Incident Database}

The primary purpose of the TrIP Incident Database is to provide transit systems with a user-friendly method to record and analyze incident data. The software also assists in collecting information pertaining to an incident. An incident can include vehicle accidents and/or any injury received by a customer, employee, or visitor.

The Incident Information Entry form (Figure 1) serves as the primary data entry site for TrIP Incident. The drop-down boxes on the form encourage incident information to be entered in a standardized manner. This enables the NCDOT to assess incidents across the state, from a variety of transit systems, in a standardized manner.

The information in most of the drop-down menus was added in collaboration with the safety administrator for the Public Transportation Division of the NCDOT. When accurately entered, the data in this incident form allows a system to determine the major causes of incidents in order to address them in future training courses. 
Figure 1

TrIP Incident Information Entry Form

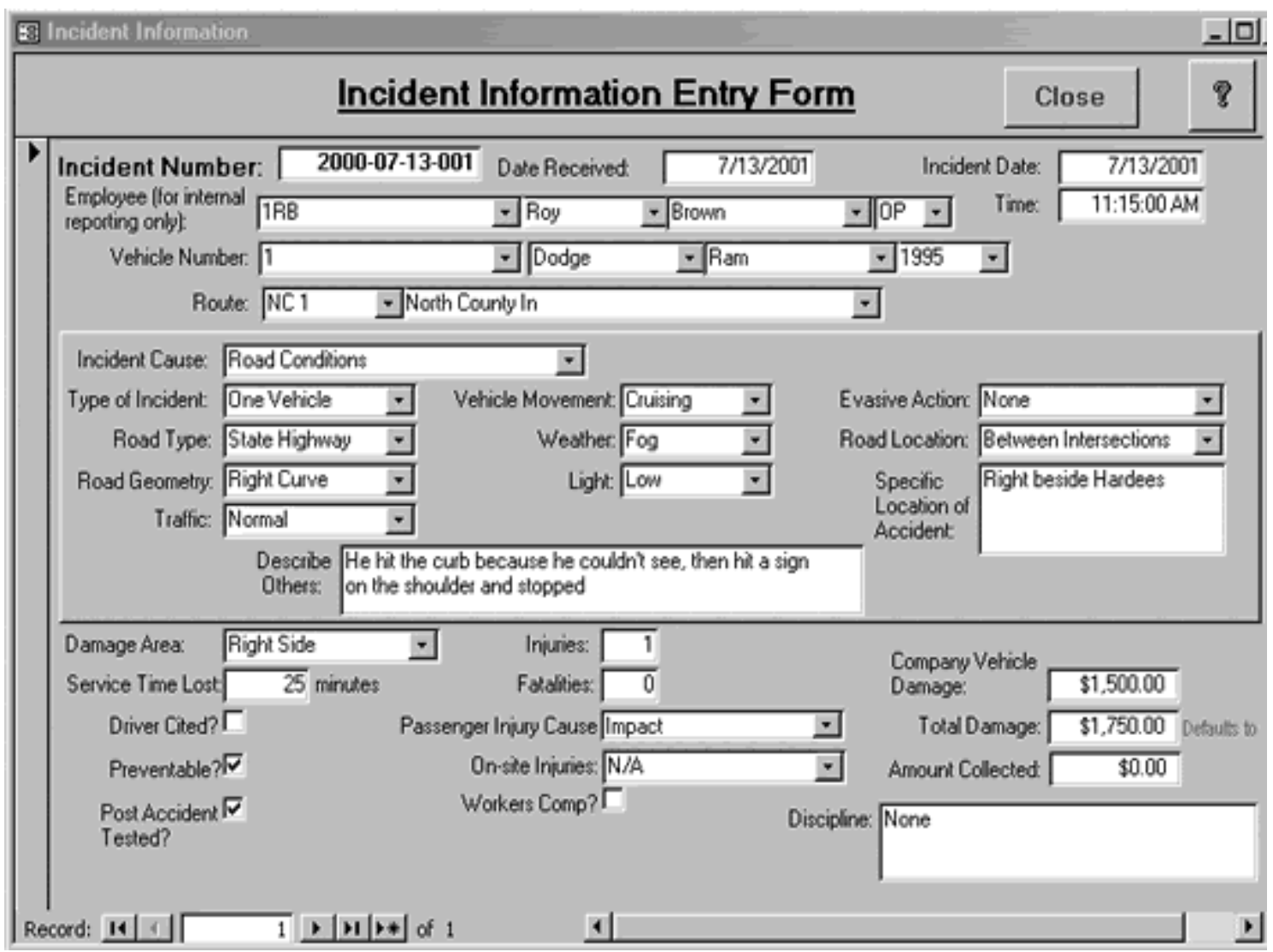

Parameters contained in the TrIP Incident Database include:

- Incident number - a unique number assigned by the user to identify each incident.

- Date received - the date that the incident is entered into the system.

- Incident date - date that the incident occurred.

- Time - time that the incident occurred.

- Employee name

- Vehicle number and type

- Route number

- Incident cause - dominant cause of the incident.

- Type of incident - vehicles involved in the incident.

- Road type - type of road.

- Road geometry - primary road characteristic where the incident occurred.

- Traffic - traffic load.

- Vehicle movement - movement of the vehicle at the time the incident occurred.

- Weather - weather type.

- Light - level of light at the time of the incident.

- Evasive action - action performed by the driver while attempting to avoid collision.

- Road location - specific location on the road where the incident occurred.

- Specific location of accident - exact location of the incident. 
- Describe others - this text box allows description of the incident.

- Damage area - the area on the vehicle that was damaged in the incident.

- Service time lost - amount of time the vehicle was out of service due to the incident.

- Driver cited - if the driver was cited.

- Preventable - was the incident preventable.

- Post-accident tested - was the driver tested for drugs and alcohol after the incident.

- Injuries - injuries associated with the incident.

- Fatalities - fatalities resulting from the incident.

- Passenger injury cause - the primary reason why passengers were injured.

- On-site injuries - who was involved in the on-site injuries.

- Worker's comp - is the worker eligible for Worker's Compensation.

- Company vehicle damage - amount of damage incurred on the company vehicle.

- Total vehicle damage - the total amount of damage resulting from the incident.

- Amount collected - how much money has been collected to date.

- Discipline - the discipline action taken for the incident.

After the incident information is entered into the database, the transit systems then submits their data quarterly to the NCDOT for review.

\section{TrIP Administration Database}

The primary purpose of TrIP Administration is to track data that is vital to a transit operation. This database stores employee information, courses taken by employees, and vehicle information.

The TrIP Administration Database Driver Training form is used to record the training that each driver has received. (It is important to track driver training to document the training program and a driver's progress for your own records and in case the driver is involved in an incident.)

Parameters included in the driver training form include:

- Training course name

- Date of the course

- Employee identifier

- Employee position

- Form of training (classroom or computer-based)

- Instructor name/agency

- Certification received

- Cost of course

- Notes necessary to describe the training the employee received.

As with the incident database, after all drivers training information is entered into the database, reports can be created at a click of a button. 


\section{Analysis of North Carolina TrIP Database}

The data collected by the TrIP databases is complete and encompasses the information necessary to analyze the data and address safety campaign issues identified by the incident data. The core set of data, and much of the supplemental set of data, has been included in the database parameters.

The ability to produce reports based on the data entered enhances a transit agency's ability to review data, draw conclusions, make recommendations, and take preventive measures to reduce the occurrence of incidents in the future. Not only does the TrIP software enable individual transit systems to keep accurate, detailed reports of incidents and driver information, it standardizes the reports so that comparisons can be made by NCDOT for transit systems statewide. By requiring all public transit systems in North Carolina to use the TrIP system and submit quarterly incident data, NCDOT is able to monitor trends and analyze the incidents occurring within the state public transit system. NCDOT can then recommend mitigation procedures or additional training that can reduce or eliminate certain types of incidents before an injury or fatality occurs. Such a tool would be useful to all states, in that all transit systems regardless of the size could utilize the resources provided. In turn, the state DOTs would have standardized data reporting which would help makes statewide analysis available. In addition, if such a system were available and used on a national level, comparisons would be easily made from state to state and region to region, regardless of system size and location.

\section{Texas}

In 2002, a report entitled "Safety Guidelines for Rural and Small Urban Transit Systems" was developed by the Texas Transportation Institute for the Texas Department of Transportation (TXDOT) outlining issues pertaining to safety for the state's small and urban transit systems. Included in the report is a section on accident management and reporting. While standardized forms are required in instances of transit accidents and incidents, there is no statewide software or database program developed for use by the transit systems. However, there is a standardized reporting form the state has developed.

The TxDOT requires that all FTA Section 5307 (small urban), Section 5310 and Section 5311 program grantees notify the Public Transportation Division (PTN) of each incident involving a transit vehicle used through the program. Each agency is required to report incidents within five days. The parameters for reporting are as follows:

- an individual dies within 30 days of a transit incident 
- an individual suffers bodily injury and immediately receives medical treatment away from the scene of the incident. Medical attention sought after leaving the scene of an incident is not reportable

- total damage exceeds $\$ 7,500$ (including other vehicles and property)

- the transit vehicle incurs disabling damage as the result of the incident and is removed from revenue service

- non-arson fire occurs in any vehicle involved in the incident, revenue facility, or non revenue facility

The PTN requires a Transit Vehicle Incident Reporting Form (Form PTN-101) (see Figure 2.) The PTN-101 form notes that the incident description should include, but not be limited to, the following basic information: causal factors of the incident, the direction in which the vehicles were traveling, and road and weather conditions. Law enforcement reports are also being submitted when available.

Figure 2

TXDOT Transit Vehicle Incident Reporting Form (Form PTN-101)

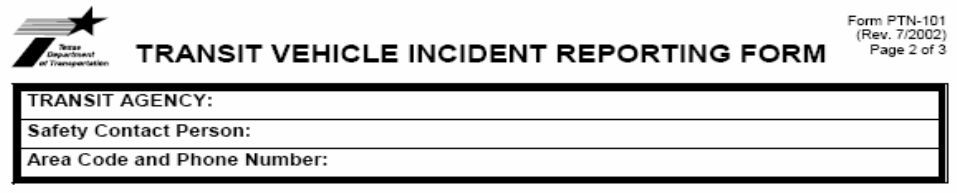

REPORTABLE FOR THE FOLLOWING REASON(S)

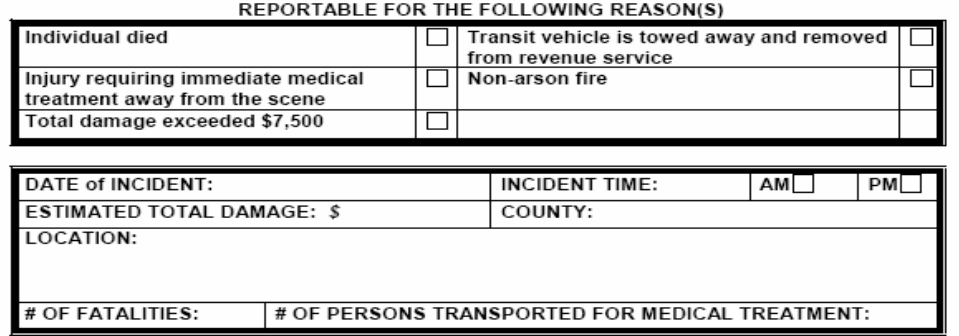

AGENCY VEHICLE INFORMATION

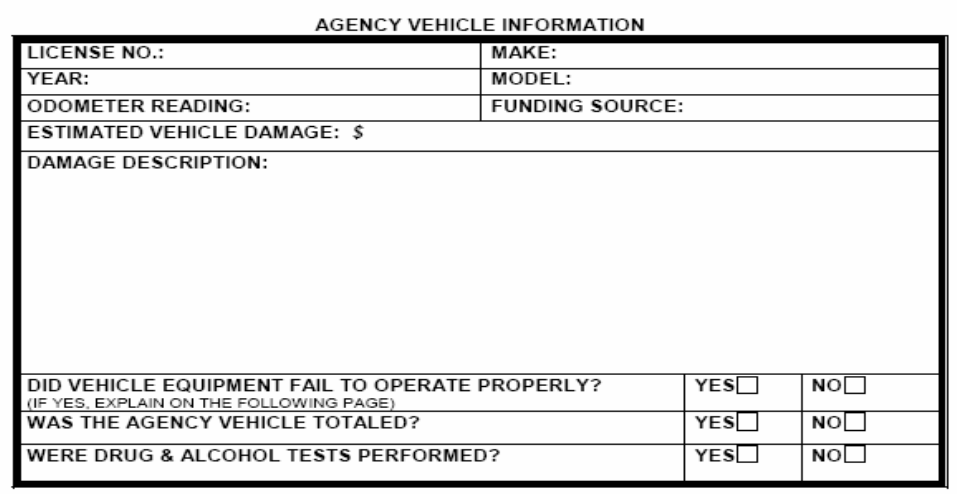

While a standardized form helps the state collect uniform information from the transit systems involved, the required information could be more comprehensive, based on the research conducted previous to this report and as noted above. 


\section{Chapter 3 Florida Bus Incident Reporting Tracking and Analysis System}

The Florida Bus Incident Reporting Tracking and Analysis System was developed for small rural agencies to provide a tool in order for them to move from manual reporting (incident data in a file cabinet) to a Microsoft Access incident database. The database program is CD-based that can be copied onto any desktop computer running Microsoft Access 2003. The database was designed to allow rural transit systems to easily enter incident data into a database, run queries and print reports that have been developed within the software. This software relieves an agency's responsibility to either develop their own or purchase a database. The program is ready to use and can be easily changed to meet the needs of the transit agency. The transit agency can view and analyze data from a set of dynamic queries on weekly, monthly or quarterly bases. The database was developed after a similar CUTR report in 2004, "Analysis of Florida Transit Bus Accidents."

The Florida Bus Incident Reporting, Tracking and Analysis System is separated into three sections: Data Entry, Data Analysis, and Reports and Charts. As seen in Figure 3.

Figure 3

Incident Reporting, Tracking and Analysis System

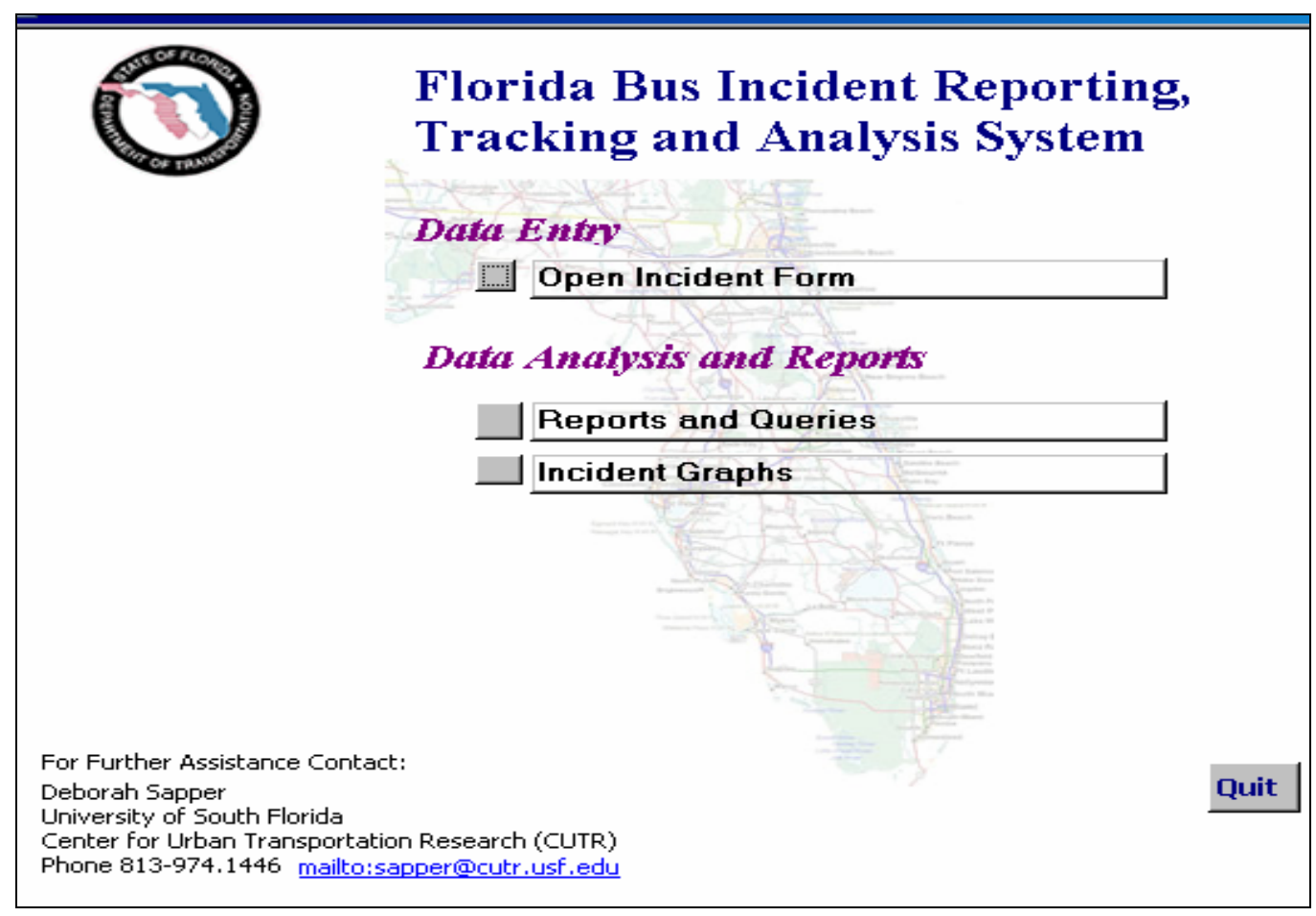




\section{Incident Form}

The Incident Form has two sections: General Information and Incident Detail. The General Information section is divided into three sections: Incident Data, Operations, and Location. The Incident Detail Section has five sections: Incident Type, Roadway, Drug and Alcohol Testing, Major Incident, and an Investigation Forms Button. The data are automatically saved when entered into the form. Data fields in Incident Reporting, Tracking and Analysis System include:

\section{General Information Section}

- Incident ID - automated number assigned by program for each incident

- Incident Number - a unique number assigned by the user identify the incident

- System Name - name of the transit system

\section{Incident Date}

- $\quad$ Month - month incident occurred (pull-down menu)

- Date - date incident occurred

- Year - year of incident (pull-down menu)

- Day of week - day of week of incident (pull-down menu)

- Time - time incident occurred

\section{Operations Data}

- Employee Number

- Hire Date - employee hired date

- Last Medical Exam - date of last medical exam

- Hours on Duty - hours driver has been on duty at the time of the incident (pull down menu)

- Last Training Date - date of training

- $\quad$ Training Type - new employee, remedial, refresher (pull down menu)

- Training Subject - operations, substance abuse, human resource, customer services, emergency management (pull down menu)

- Bus Number

- Vehicle VIN Number

- Bus Route

- Manufacturer - bus manufacturer (pull down menu)

- Year of Manufacturer - year bus was built (pull down menu)

- Last Vehicle inspection- date

\section{Location}

- On/At Street

- City

- Intersection - near side, far side, in intersection (pull down menu)

- Location - at stop, approaching stop, leaving stop, between stops, loading, unloading (pull down menu)

- At or Near

- City

- Latitude

- Longitude

\section{Incident Detail Section}

Incident Type

- Collision - object, vehicle, pedestrian, bike, motorcycle, other (pull down menu)

- Involvement type - one vehicle, two vehicle, pedestrian, fixed object, onboard passenger, boarding passenger, alighting passenger, on-site, bus stop, station (pull down menu) 
- Incident Location - bus stop, intersection, pull out, 4 way stop, traffic light (pull down menu)

- Evacuation- fire/smoke, security incident, flammable fuel, hazard material, (pull down menu)

- Evacuation Location - transit center, shopping center, residential, commercial, non-profit, other (pull down menu)

- Security Incidents - aggravated assault, arson, bombing, bomb threat, burglary, chemical or biological release, hijacking, homicide, larceny/theft, vehicle theft, robbery, sabotage, vandalism (pull down menu)

- Other Incident - slip/falls, wheelchair/mobility devices, wheelchair lift/ ramps(pull down menu)

Roadway

- Wheelchair Lift Manufacturer

- Roadway Type - city street, county road, state hwy, interstate, parking lot, private(pull down menu)

- Traffic Condition - heavy, medium, light(pull down menu)

- Impact - rear end, sideswipe, angle, backing, head-on, front(pull down menu)

- Roadway Condition - dry, wet, gravel, debris, graded, dirt, ice/snow

- Weather - clear, cloudy, fog/mist, rain, wind, snow/ice

- $\quad$ Light - daylight, dawn, dusk, dark

Drug and Alcohol Testing

- Was FTA Criteria for post accident drug and alcohol testing met - Yes/No

- Was Testing Conducted - Yes/No

- Results Received -Yes/No

Major incidents

- $\quad$ Fatalities-Yes/No -

- Injuries-Yes/No

- Property Damage over $\$ 1000-Y e s /$ No

- Estimated Property Damage

- Preventability Status -preventable/non-preventable

- Corrective Action -retraining, disciplinary, policy change, operational change(pull down menu)

The variables and pull down menus were developed using some of the variables identified by the Federal Transit Administration's (FTA's) National Transit Database (NTD), Safety and Security Module and input from transit systems in the state. The forms are shown in Figure 4 and Figure 5. 
Figure 4

General Information Form

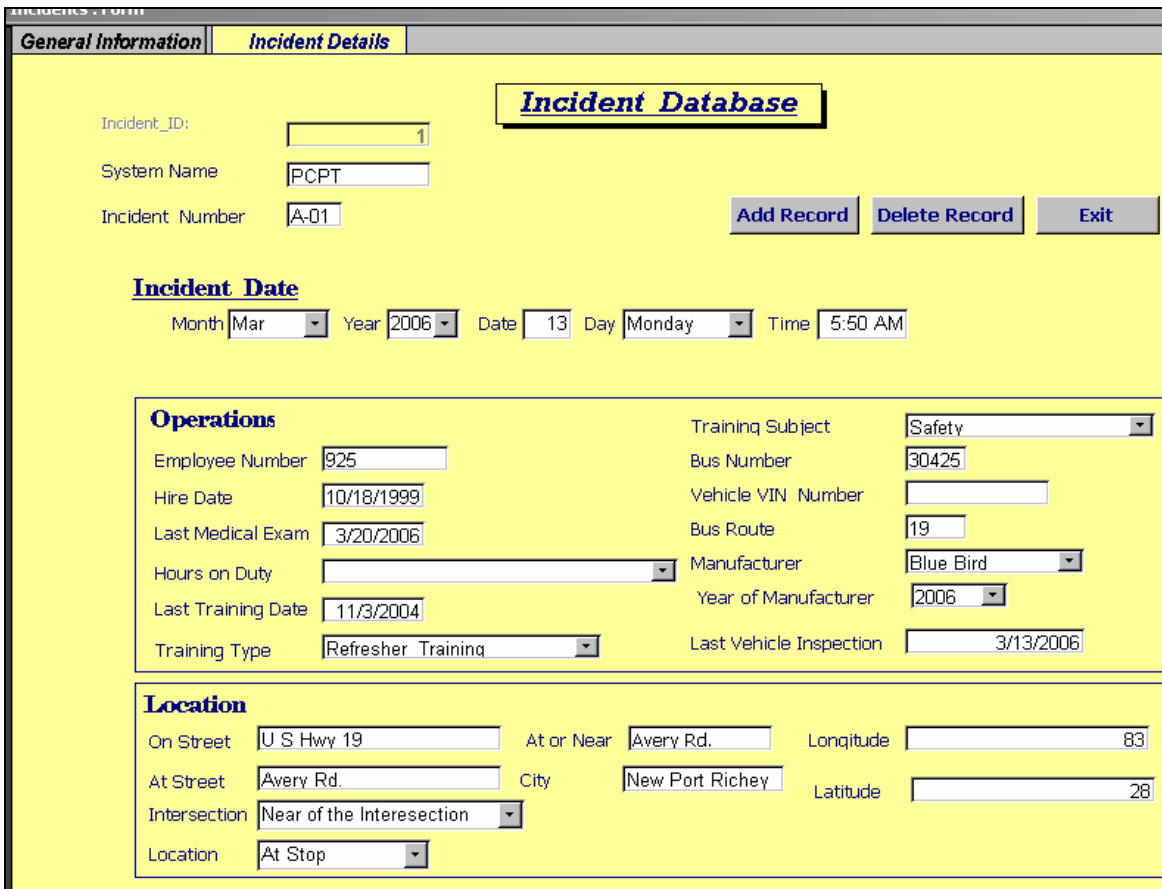

Figure 5

Incident Details

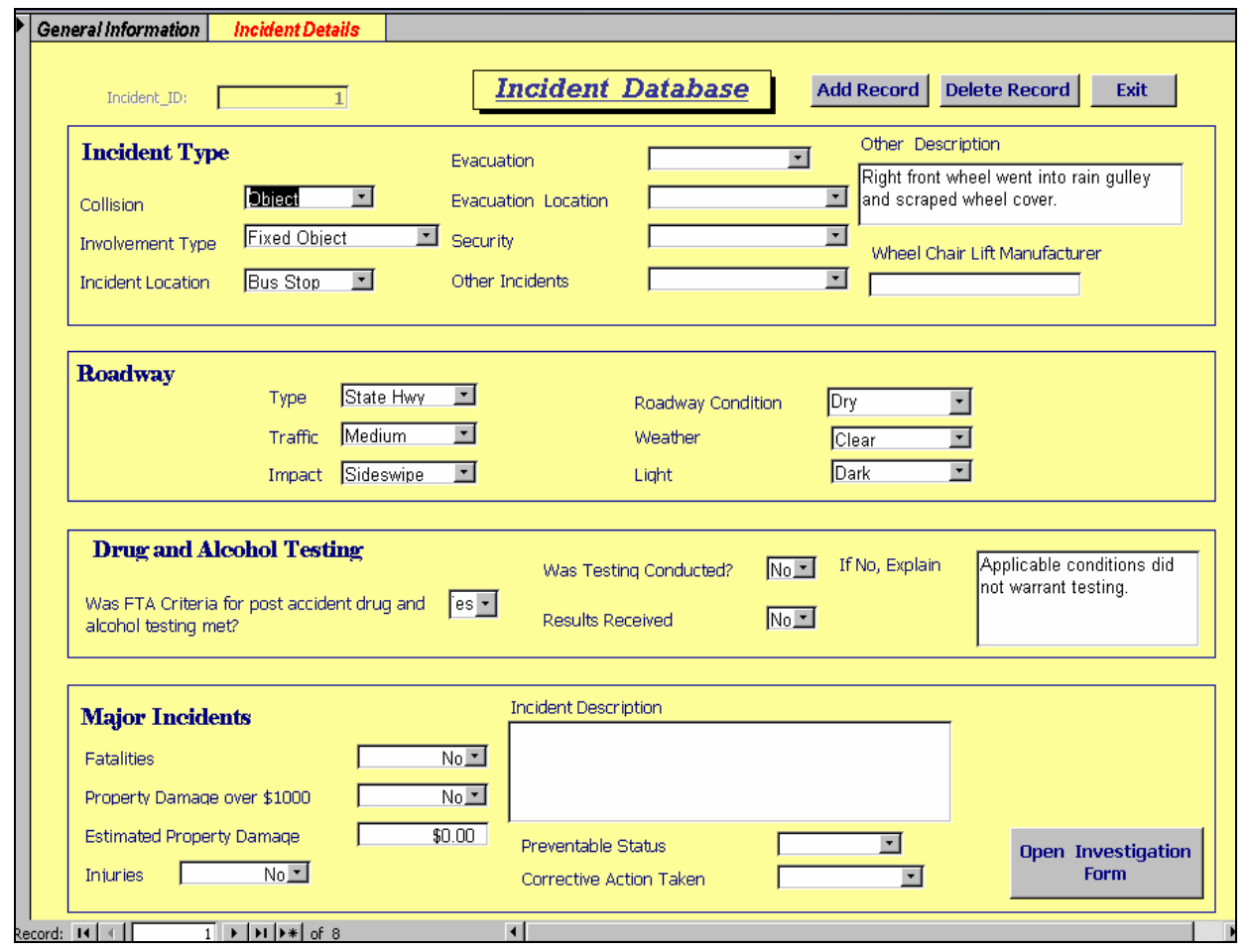




\section{Incident Investigation Form}

The Open Investigation Form button will be activated only if one of three fields in major Incidents: Fatalities, Property Damage over $\$ 1000$, or Injuries has been checked "Yes." An example is shown in Figure 6. This form will help transit systems meet the Chapter 14-90.004, FAC, Bus Transit System Operational Standards cited on page 4 of this report.

Figure 6

Incident Investigation Form

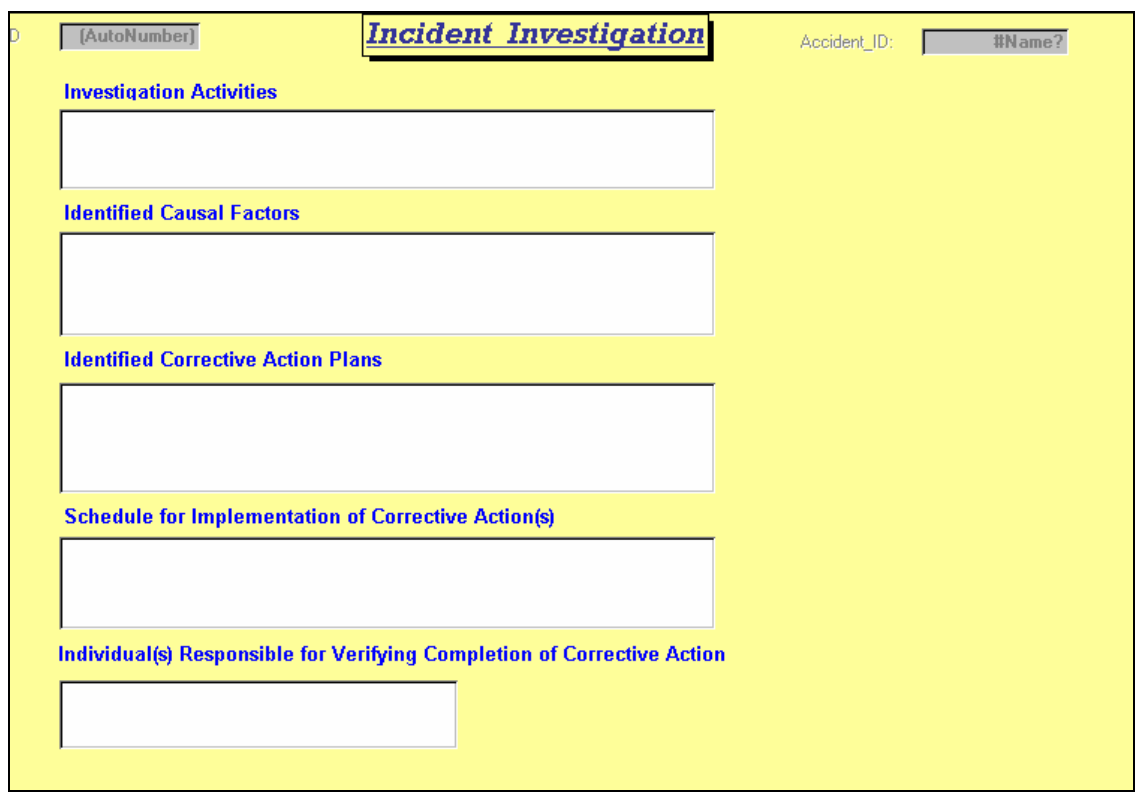

\section{Data Analysis and Reports Sections}

The Data Analysis and Reports section allows for analysis of data on twenty-nine variables as seen in Figure 7. The queries and reports are run by clicking on any of the twenty-nine query choices. The program then runs the query and assembles the data into a report format that is ready to print. The Data Analysis and Report section includes the following predefined queries and reports:

- Bus Manufacturer - Bus Manufacturer, Year, Accident Number, Vehicle VIN, Bus Number

- Bus Routes - Bus Route, Frequency, Employee Number

- Collision - Accident Number, Collision, Incident, Involvement Type, Bus Route

- Corrective Action - Corrective Action, Incident Number

- Date and Time of Incident - Incident, Month, Date, Year, Day of Week, Time, Employee Number

- Drug Alcohol - Accident Number, Employee Number, FTA Criteria Met, Was Testing Conducted, Results Received

- Employee History - Employee Number, Accident Number, Hire Date, Last Training, Training Date, Last Medical, Hours on Duty, Collision Type

- Estimated Property Damage - Estimated Property Damage, Bus Number, Employee Number, Vehicle VIN 
- Evacuation - Evacuation Type, Accident Number, Vehicle VIN, Bus Number ,Bus Route, Employee Number

- Incident Type - Accident Number, Employee Number, Bus Route, Collision Type, Security Type, Other

- Impact - Impact, Accident Number, Employee Number, Vehicle VIN, Bus Route

- Involvement Type - Involvement Type, Accident Number, Vehicle VIN Number, Bus Number, Employee Number

- Last Vehicle Inspection - Vehicle VIN Number, Date, Last Vehicle Inspection

- $\quad$ Light - Light Condition, Incident Number, Bus Route

- Light Conditions - Light Condition, Frequency, Distribution

- Location - Bus Route, Accident Number, Employee Number, On Street, At Street, At or Near, Location, Latitude, Longitude

- Month - Month. Frequency, Distribution

- Other Incidents - Other Incidents, Incident Number, Employee Number, Bus

- Property Injuries Fatalities - Employee Number, Accident Number, Property Damage, Fatalities, Injuries, Estimated Property

- Road Conditions - Roadway Condition, Frequency, Distribution

- Road Characteristics - Incident Number, Employee Number, Bus Route, Bus Number, Roadway Type, Roadway Condition, Light, Traffic

- Roadway Type - Roadway Type,Frequency, Distribution

- Security - Security Type, Bus Route, Employee Number, Accident Number

- Time of Day -Time of Day, Frequency, Distribution

- Traffic Conditions - Traffic Conditions, Frequency, Distribution

- View by Preventability - Preventable/Non-Preventable, Frequency, Distribution

- Weather Conditions - Bus Route, Accident Number, Employee Number, Weather Condition, Roadway Condition

- Wheelchair/Other Incidents - Accident Number, Vehicle VIN Number, Number Route, Incident Type, Wheelchair Lift Manufacturer

Figure 7

Data Analysis and Report Section

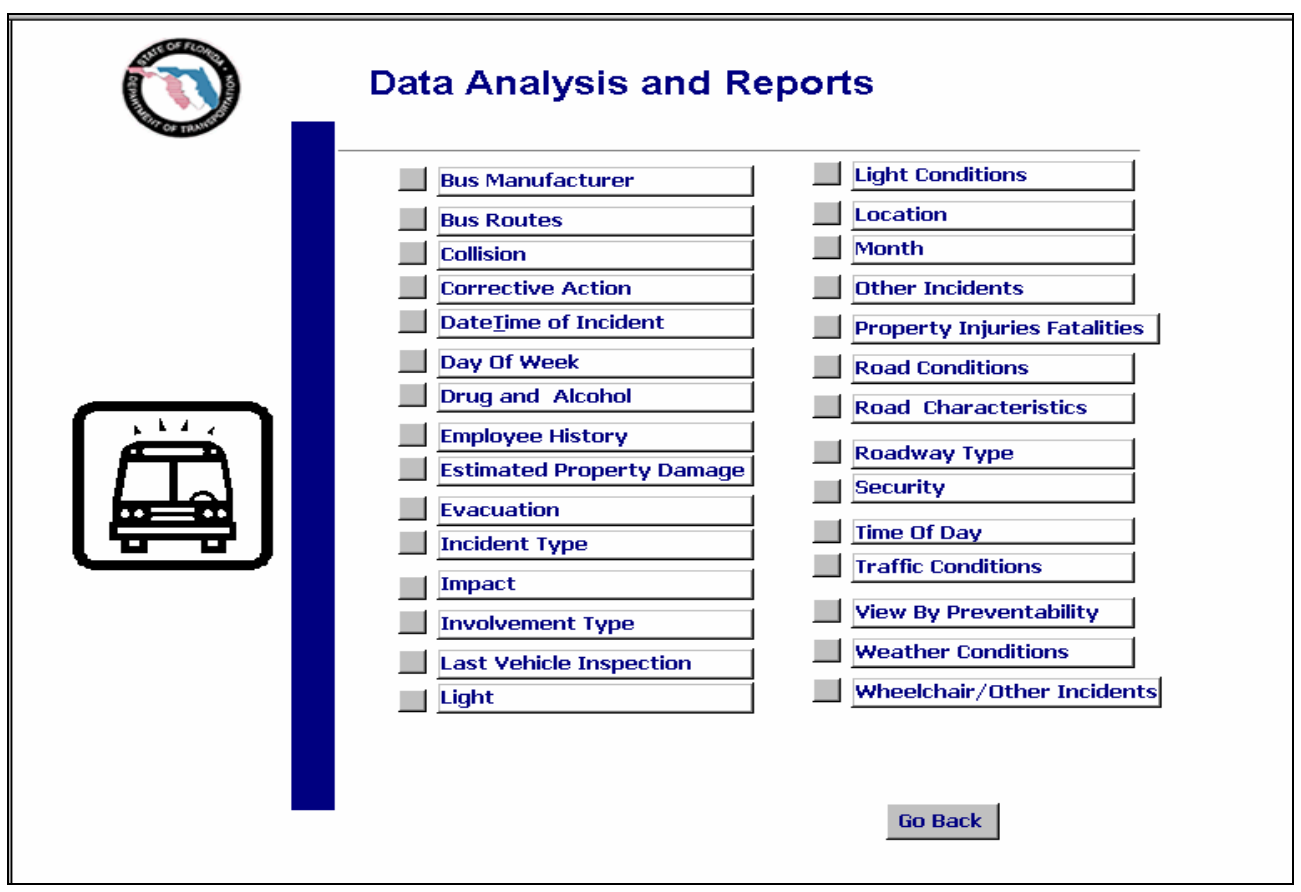


Tables 1 through 3 include examples of queries using Pasco County Public Transportation (PCPT) data and reports that are available to analyze data.

Table 1

Road Characteristics

\begin{tabular}{|l|l|l|l|l|l|l|l|}
\hline $\begin{array}{l}\text { Incident } \\
\text { Number }\end{array}$ & $\begin{array}{l}\text { Employee } \\
\text { Number }\end{array}$ & $\begin{array}{c}\text { Bus } \\
\text { Route }\end{array}$ & $\begin{array}{c}\text { Bus } \\
\text { Number }\end{array}$ & $\begin{array}{c}\text { Roadway } \\
\text { Type }\end{array}$ & $\begin{array}{l}\text { Roadway } \\
\text { Condition }\end{array}$ & \multicolumn{1}{|c|}{ Light } & Traffic \\
\hline A-01 & 92 & 19 & 30425 & State Hwy & Dry & Dark & Medium \\
\hline A-02 & 94 & 23 & 26968 & Parking Lot & Dry & Daylight & Light \\
\hline A-03 & 94 & 23 & 22813 & County Road & Dry & Daylight & Light \\
\hline A-04 & 98 & 33 & 21938 & County Road & Dry & Daylight & Medium \\
\hline A-05 & 94 & 19 & 25118 & County Road & Dry & Daylight & Light \\
\hline A-06 & 94 & 23 & 26968 & County Road & Dry & Daylight & Light \\
\hline A-07 & 98 & 21 & 21408 & State Hwy & Dry & Daylight & Medium \\
\hline
\end{tabular}

Table 2

Date of Incident

\begin{tabular}{|c|c|c|c|c|c|c|}
\hline $\begin{array}{c}\text { Incident } \\
\text { Number }\end{array}$ & Month & Date & Year & $\begin{array}{c}\text { Day of } \\
\text { Week }\end{array}$ & Time & $\begin{array}{c}\text { Employee } \\
\text { Number }\end{array}$ \\
\hline A-01 & Mar & 13 & 2006 & Monday & 5:50:00 AM & 925 \\
\hline A-02 & Mar & 22 & 2006 & Wednesday & 5:10:00 PM & 944 \\
\hline A-03 & Mar & 27 & 2006 & Monday & 1:04:00 PM & 941 \\
\hline A-04 & Mar & 28 & 2006 & Tuesday & 8:00:00 AM & 980 \\
\hline A-05 & Apr & 6 & 2006 & Thursday & 11:35:00 & 947 \\
\hline A-06 & Apr & 14 & 2006 & Friday & 3:22:00 PM & 944 \\
\hline A-07 & Apr & 26 & 2006 & Wednesday & 2:55:00 PM & 982 \\
\hline A-08 & May & 9 & 2006 & Tuesday & 8:07:00 AM & 917 \\
\hline
\end{tabular}


Table 3

Collision Type

\begin{tabular}{|c|c|c|c|c|}
\hline $\begin{array}{c}\text { Accident } \\
\text { Number }\end{array}$ & Collision & Incident & Involvement & $\begin{array}{c}\text { Bus } \\
\text { Route }\end{array}$ \\
\hline A-01 & Object & Bus Stop & Fixed Object & 19 \\
\hline A-02 & Vehicle & Bus Stop & Two Vehicle & 23 \\
\hline A-03 & Vehicle & Bus Stop & Two Vehicle & 23 \\
\hline A-04 & Vehicle & Traffic Light & Two Vehicle & 33 \\
\hline A-05 & Motorcycle & Bus Stop & Two Vehicle & 19 \\
\hline A-06 & Vehicle & Bus Stop & Two Vehicle & 23 \\
\hline A-07 & Object & & & 21 \\
\hline A-08 & Vehicle & Bus Stop & One Vehicle & 19 \\
\hline
\end{tabular}

\section{Incident Graphs Section}

The Incident Graph section provides graphic capabilities to help transit systems analyze their data, as shown in Figure 8.

Figure 8

Incident Graphs Section

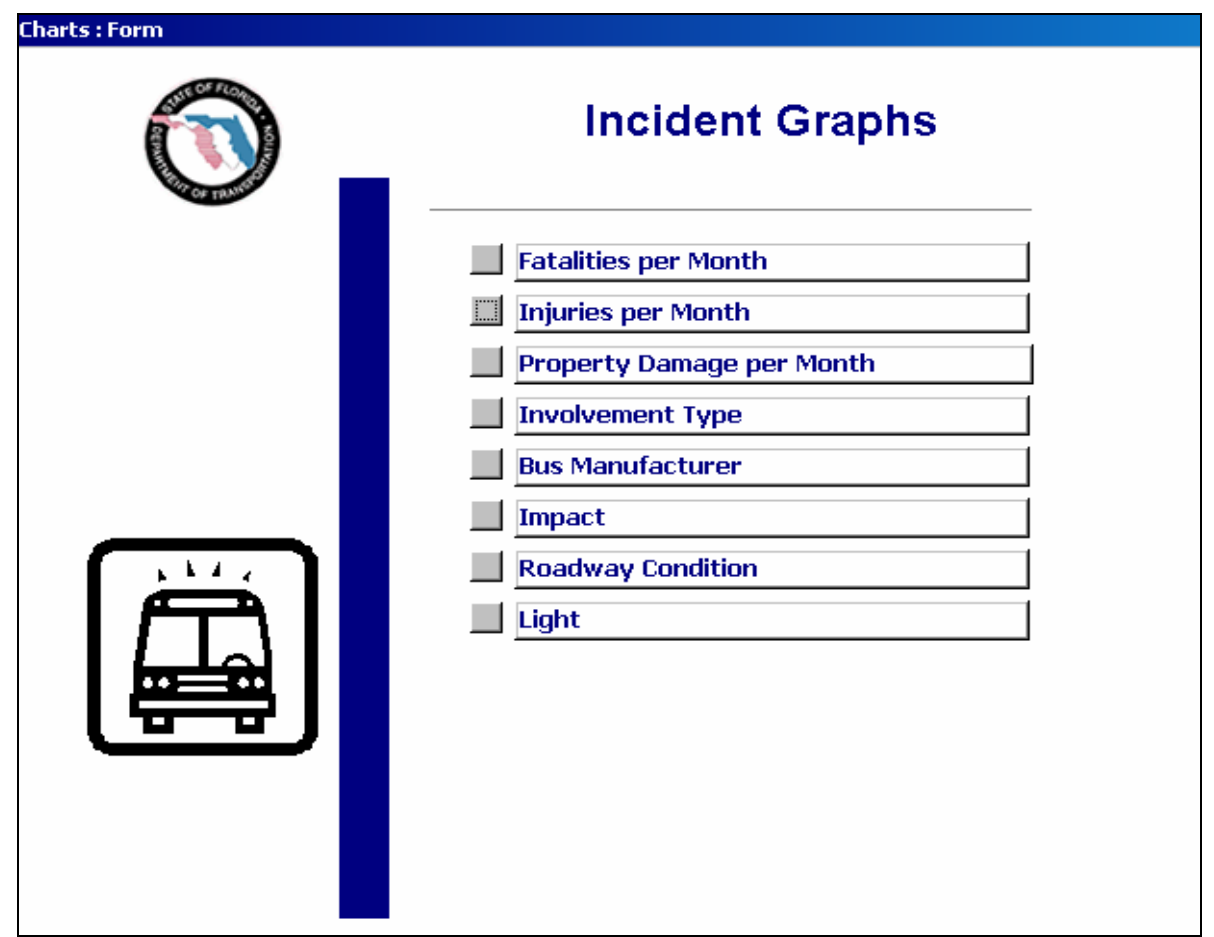


Figures 9 through 11 are examples of graphs that are available in the Incident Graph Section.

Figure 9

Bus Incidents by Manufacturer

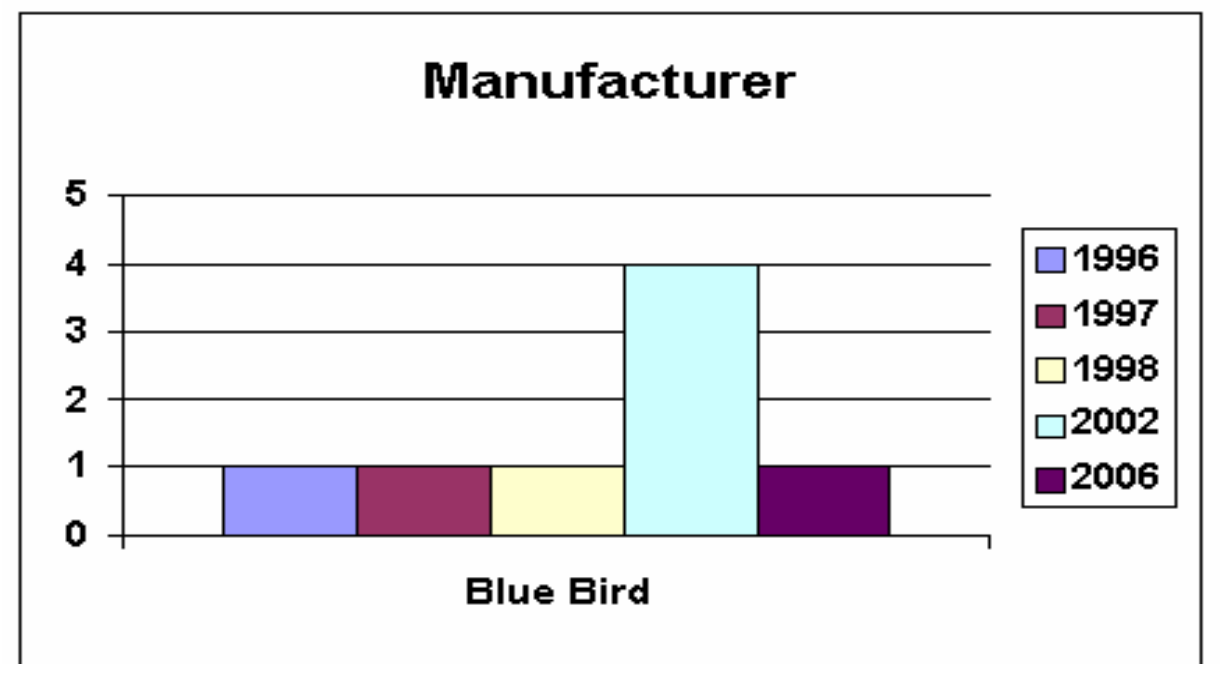

Figure 10

Bus Incidents by Impact Location

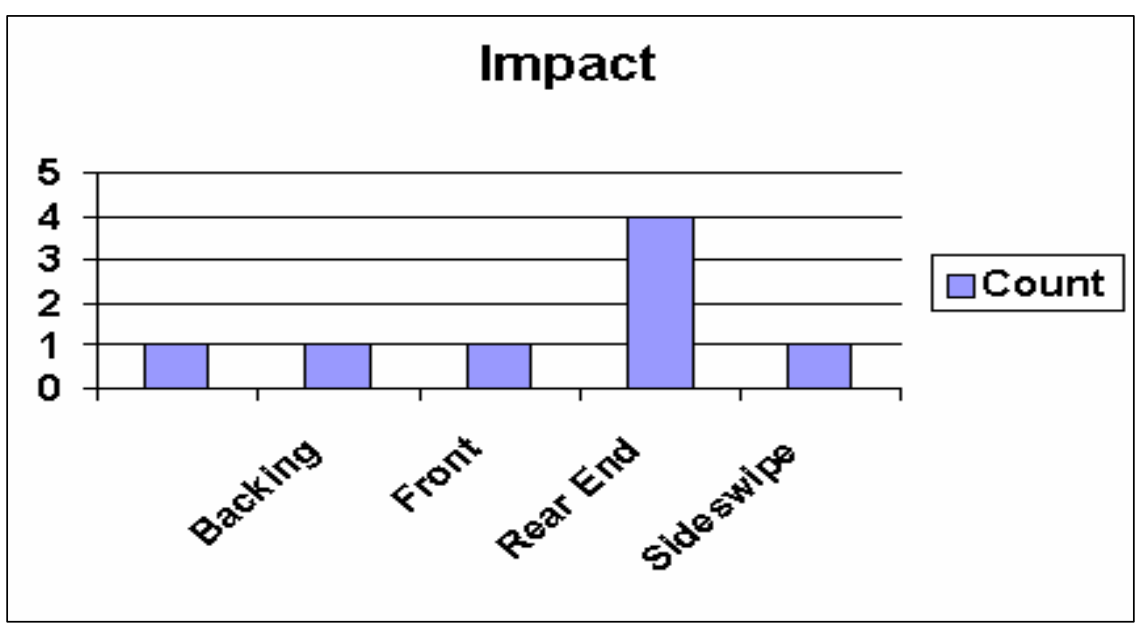


Figure 11

Bus Incident by Lighting Type

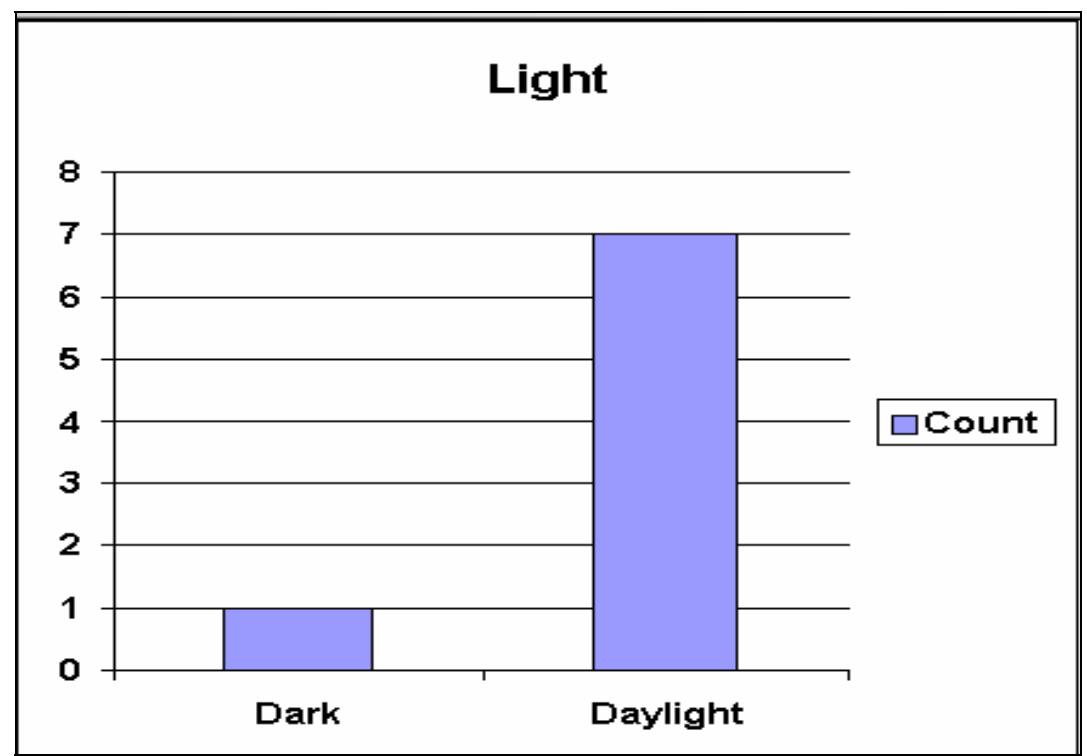

\section{Beta Testing/Peer Reviews}

Once a fully functional version of the Florida Bus Incident Reporting, Tracking and Analysis System was completed, it was important to have users test the system. Although CUTR did not anticipate any problems associated with environmental specifications such as operating platforms or hardware requirements. CUTR needed to determine if there were any system flaws, functional issues or whether there were any other variables that needed to be included in the database.

In February 2006, four Florida rural transit properties were selected to beta test the Bus Incident Reporting, Tracking and Analysis System: Pasco County Public Transportation, LeeTran, Collier Area Transit, and Polk County Transit Services. Each agreed to be beta users and test the software for two months. During this time, CUTR researchers maintained open lines of communication with the beta users to answer questions, receive comments, and report issues or problems. Although none of the transit system identified any significant functionality issues, several systems had an older version of Microsoft Access which impeded their ability to test the system. However, in each case, the user made upgrades to their computers to successfully use and test the system. Overall, the transit systems were very excited about the Bus Incident Reporting, Tracking and Analysis System. The transit systems felt, that this was a tool they needed in order for to track and analyze their systems incidents. It was 
also very easy to use and modify to meet their needs and they were very anxious to receive a copy of the software.

A few minor changes where made to the Bus Incident Reporting, Tracking and Analysis System program, reflecting the comments from beta users. The changes included adding the Vehicle Identification Number (VIN), adding a field for corrective actions, and adding queries and graphs to the program. The VIN will be used in the future to link the Bus Incident Reporting, Tracking and Analysis System with the Florida Vehicle Maintenance Database currently under development by CUTR. By linking the two databases by the VIN, information will be available regarding when the vehicle was last serviced, the person performing the maintenance, and type of maintenance that was performed on the vehicle, as well as the history of the vehicle before the incident occurred.

Also during this time, two other Florida transit systems, Hillsborough Area Transit Authority (HART) and Gainesville Regional Transit System (RTS) requested copies of the beta version of the Bus Incident Reporting, Tracking and Analysis System program. HART was interested in using the program in the interim until its Risk Management Program was in place. RTS needed an incident management program and indicated that they did not have the time to develop the incident software program. Development of this program was far enough along that they were able to start using this program immediately while still being able to easily add fields and queries that met their agencies needs. RTS has been using the system with only minor changes to the program. 


\section{Chapter 4 Future Web Based Incident Tracking Database}

As transit systems become more efficient, a transit incident database is an important tool to keep track of all accidents, security, and safety related incidents. Accidents, for instance, can be very costly, and post-event activities can be time consuming and can result in negative consequences for transit systems, employees, shareholders and the customers/riders. Therefore, any tools that can assist a transit system in monitoring, tracking and identifying incident trends can be beneficial by identifying corrective action to prevent these types of action from reoccurring in the future.

As with any computer application, the incident tracking database can be developed for both desktop users and/or web-base users. For this project, the incident database was developed for desktop users and enabled transit systems to track, analyze and report data. The database was designed for transit systems that had no other means of electronically tracking incidents. Developing a desktop web-based incident tracking program is a task that FDOT's Public Transit Division envisions for the future. The future vision, once a thorough needs assessment is completed, is for a web-based, statewide incident tracking system.

While the desktop application version of the incident tracking software has proven to be easy to implement, there are many factors that need to be considered when researching the feasibility of developing and maintaining a web-based incident tracking database. A web-based system will require a significant amount of funding for capital equipment purchases (hardware), technical support staff, and long term maintenance costs including hardware, software and security upgrades. FDOT will also need to provide staff to collect, analyze and report the data from a statewide web-based incident tracking database.

Microsoft's SQL Server is the industry's web-based system of choice. Microsoft SQL is a comprehensive, integrated, end-to-end data solution that provides a secure, reliable, and productive platform for data applications. SQL Server 2005 delivers powerful, familiar tools to information technology professionals, as well as to information workers, reducing the complexity of creating, deploying, managing, and using data and analytical applications on platforms. SQL Server 2005 provides a complete data solution for government and businesses of all sizes. ${ }^{1}$

${ }^{1}$ http://www.microsoft.com/sql/prodinfo/overview/default.mspx 
There are eight different editions of Microsoft SQL server. The least expressive can cost several thousand dollars and the most expensive can cost tens of thousands of dollars. However, the purchase price is only part of the overall costs. In general, buying software is simple, but when dealing with the purchase of Microsoft SQL Server, it becomes immensely more complicated. With the purchase of several editions of Microsoft SQL Server comes an array of licensing issues that can add significant costs and be a logistical challenge.

However, while investigating the cost benefits and feasibility of instituting a statewide web-based system such as SQL, there are questions that need to be addressed. How will the computer MS-SQL server be maintained? How will the MSSQL server be administrated? Who will migrate, repair or expand the data tables? Who will respond to security break-ins and prevent/mitigate hacking? Who and how will data be backed up and the storage of data be coordinated offsite? Who will upgrade the hardware for the MS-SQL server? Who will coordinate statewide access to the SQL server? Who will maintain the UPS battery and ensure proper shutdown of the SQL in case of a blackout to prevent corruption?

\section{Table 4}

\section{Comparing the Positives and Negatives of a Desktop and Web-Based Incident Reporting System}

\begin{tabular}{|c|c|c|}
\hline & Desktop Application using MS Access & $\begin{array}{l}\text { Web-based application using MS Visual Web } \\
\text { Developer and SQL Server Express }\end{array}$ \\
\hline Positives & $\begin{array}{ll}\text { - } & \text { Easy to develop and implement } \\
\text { - } & \text { No installation/download } \\
\text { - } & \text { Existing familiarity with MS Access } \\
\text { - } & \text { Easilegration with MS Office } \\
\text { - } & \text { Most functionized } \\
& \text { Access help Wizards achieved using } \\
\text { - } & \text { Help } \\
\text { - } & \text { Very little technical support needed } \\
\text { - } & \text { Relatively inexpensive }\end{array}$ & $\begin{array}{l}\text { - } \text { Availability through an Intranet and/or the } \\
\text { Internet } \\
\text { - } \quad \text { Capability to allocate/manage security } \\
\text { - } \quad \text { Easy scalability from SQL Server Express to } \\
\text { - } \quad \text { Rep Server } \\
\text { - } \quad \text { Capability of generating Dynamic Reports } \\
\text { - } \quad \text { Data is stored in one location }\end{array}$ \\
\hline Negatives & $\begin{array}{ll}\text { - } & \text { Requires Microsoft Office } 2000 \text { or } \\
& \text { later } \\
\text { - } & \text { Access database limitations }\end{array}$ & $\begin{array}{ll} & \text { More time for development and Implementation } \\
\text { - } & \text { More complex to achieve the same functionality } \\
\text { - } & \text { Require IT expertise } \\
\text { - } & \text { Requires continual maintenance } \\
\text { - } & \text { Implementation can be costly } \\
\text { - } & \text { Require capital hardware and software } \\
& \text { purchases } \\
\text { - } \quad \text { Requires upgrades and backups }\end{array}$ \\
\hline
\end{tabular}

Initially, it is advisable that transit systems start with the desktop application to become accustomed to the system and become familiar with the process of entering field data into the database, and generating reports and graphs. Once the transit 
systems become comfortable with the desktop application then the FDOT can determine if there is a significant need or advantage to developing a web-based system. The Bus Incident Reporting, Tracking and Analysis System will allow for easy conversion of data, queries and reports when a decision is made to develop a statewide transit bus web-based reporting system. 


\section{References}

Dennis Hinebaugh, "Enhancing Safety in Florida Transit Systems, Technical Memorandum Number One - Survey of Public Transit Operators”, June 1998, Center for Urban Transportation Research (CUTR).

Joel Rey, Dennis Hinebaugh, Jose Fernandez”, Analysis of Florida Transit Bus Crashes, Final Report”, June 2001; Center for Transportation Research, NCTR Report 392-05

Florida Administrative Code; Chapter 14-90; http://fac.dos.state.fl.us/faconline/chapter14.pdf

Deborah Buchacz Sapper, Oliver Page; “Analysis of Florida Transit Bus Accidents”; December 2004, Center for Transportation Research, NCTR Report 527-11

New York Public Transportation Safety Board (PTSB) http://www.dot.state.ny.us/ts/ptsb.html

Katherine F. Turnbull, Laura L. Higgins, Cynthia A. Weatherby Gilliland, “Safety Guidelines for Rural and Small Urban Transit Systems”, April 2003, Texas Transportation Institute, Product 04008-P1

“TrIP”, Institute for Transportation Research and Education (ITRE) at North Carolina State University http://itre.ncsu.edu/transit/TrIP/TrIP_Incident.htm 


\section{Appendix A}

Florida Department of Transportation, Fixed Guideway Transportation System Online Safety and Security Oversight Document Management 


\section{Florida Department of Transportation, Fixed Guideway Transportation System Online Safety and Security Oversight Document Management}

As part of this project's scope CUTR provided technical assistance to the FDOT Public Transit and Technology offices for developing page layouts and content for the FDOT Fixed Guideway Transportation Systems Online SSO Document Management website. This task involved technical assistance in developing the reporting forms, layouts and checklist for the website.

The FDOT Fixed Guideway Transportation Systems Online SSO Document Management Program web site is used to assist and facilitate the implementation of the SSO program and oversight requirements. The FDOT Public Transit Offices intends the web site to be used by the Fixed Guideway Transportation Systems (FGTS) for notification of any reportable events or hazards, and electronic submittal of System Safety Program Plans (SSPP), incident reports, investigation procedures, corrective actions plans, and implementation schedules and status reports. FDOT will then notify the FGTS of acceptance/rejection of the SSPP, incident reports, investigation procedures, corrective actions plans and implementation schedules, corrective actions plans, and implementation schedules through a series of checklists forms that the FDOT Public Transit Office will electronically transmit to FGTS. A copy of Online SSO Document Management page is shown below. 


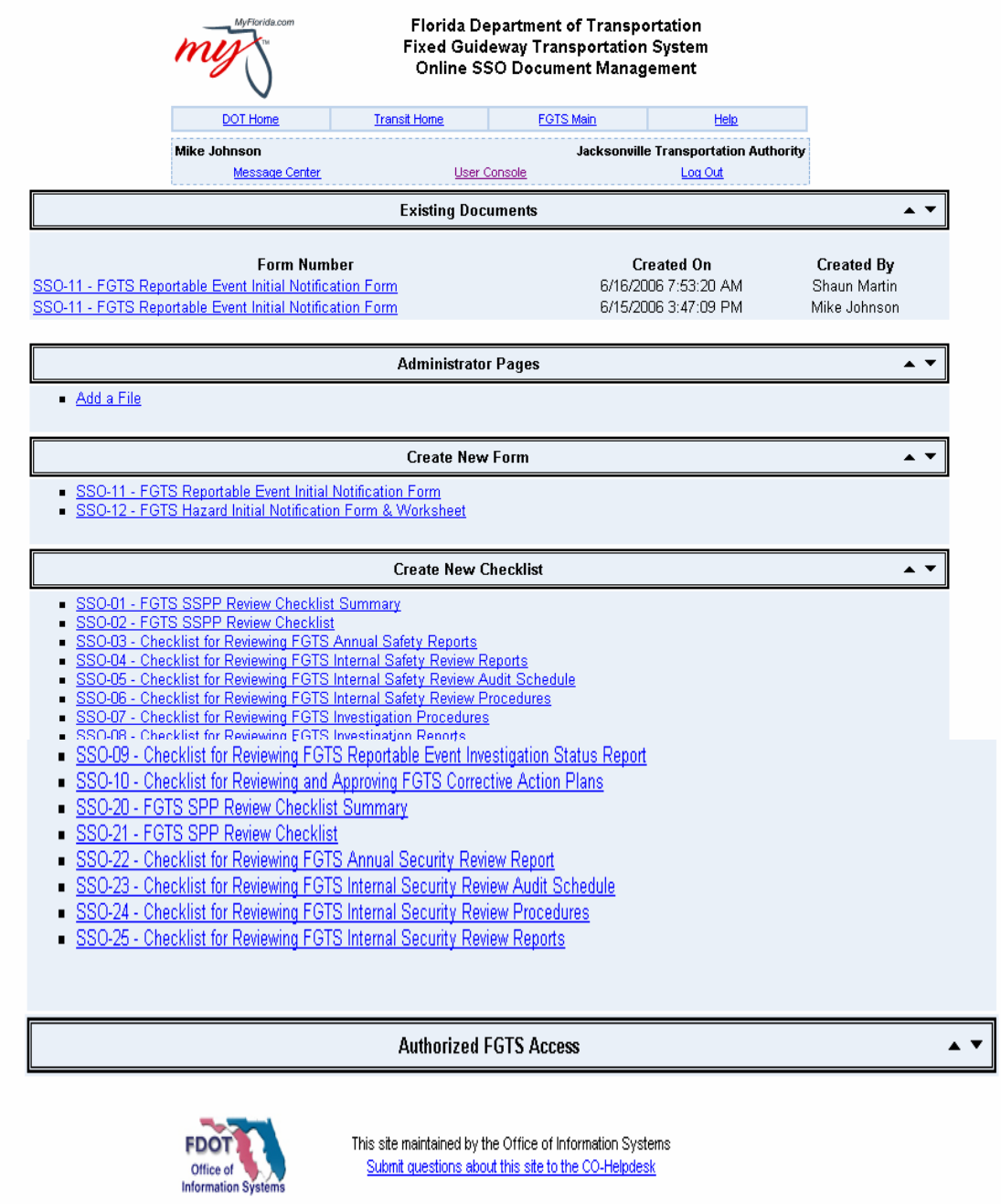

Online SSO Document Management Page

The SSO Manual, SSO forms, and checklists are available on the web site to be downloaded and completed on-line. The SSO Document Management website address is www2.dot.state.fl.us/SafetySecurityOversight. The SSO web site is a secure website, with password controls to ensure secure access. 
